\section{Season and Cultivar Influence the Fruit Quality Response of Apple Cultivars to Particle Film Treatments}

\author{
D. Michael Glenn ${ }^{1}$,
} Stephen Drake ${ }^{2}$,

Judith A. Abbott ${ }^{3}$,

Gary J. Puterka ${ }^{4}$, and

Patricia Gundrum ${ }^{5}$

Additional IndeX words. Malus sylvestris var. domestica, kaolin, 'Gala', 'Empire', 'Fuji', 'Cameo', firmness, color, hue angle, soluble solids, starch index, taste panel

SuMMARY. Experiments were performed over 3 years to examine the effect that particle film (PF) treatment had on fruit quality of several apple (Malus $\times$ domestica) cultivars in Washington and West Virginia. In the first study, a highly reflective, white, hydrophilic particle-based kaolin mineral (Surround WP) was applied to 'Empire' apple in May and June, on a season-long basis, or not at all. Red fruit color was increased by both the PF treatments compared with no treatment in all years. In a second study, the PF material was applied, starting at petal fall, every week for 6 weeks and then every 2 weeks until harvest to 'Empire', 'Gala', and 'Fuji' trees in West Virginia and to 'Cameo', 'Fuji', and 'Gala' trees in Washington. In the latter study, cultivar response

U.S. Department of Agriculture, Agricultural Research Service (USDA-ARS)

The authors wish to thank the Washington State Tree Fruit Research Commission and the Engelhard Corporation for their financial support of this research.

${ }^{1}$ Soil Scientist, USDA-ARS, Appalachian Fruit Research Station, 45 Wiltshire Road, Kearneysville, WV 25430. E-mail: mglenn@afrs.ars.usda.gov

${ }^{2}$ Horticulturist, USDA-ARS, Tree Fruit Research Laboratory, Wenatchee, WA 98801-1299.

${ }^{3}$ Horticulturist, USDA-ARS, Produce Quality and Safety Laboratory, Beltsville, MD 20705

${ }^{4}$ Entomologist, USDA-ARS, Appalachian Fruit Research Station, 45 Wiltshire Road, Kearneysville, WV 25430.

${ }^{5}$ Support Plant Pathologist, USDA-ARS, Appalachian Fruit Research Station, 45 Wiltshire Rd., Kearneysville, WV 25430. to season-long applications varied by year and location. 'Empire' consistently had improved red color with season-long applications of PF materials. 'Gala' had greater fruit weight and red color with PF application in 1 of 2 years in West Virginia but not in Washington. 'Fuji' had greater fruit weight and soluble solids content and 'Cameo' had greater soluble solids, higher starch indices, and greater red color in Washington with the PF application. In these studies, application of a PF never reduced the surface red color in apples. A taste panel did not identify quality differences in 'Empire' apples treated with $\mathrm{PF}$ vs. the control. Cultivar responses to $\mathrm{PF}$ applications were variable due to location and yearly environmental characteristics. While particle film technology has value for insect control and reducing sunburn, it has limited value to enhance fruit color due to the inconsistent response.

A pple ripening and maturity are complex developmental processes (Abeles et al., 1992; Walter, 1967) and vary by location, rootstock, and year due to the environmental and cultural practices of each growing season (Boynton and Burrell, 1944; Blizzard et al., 1988; Heinicke, 1966; Robinson et al., 1991; Unrath, 1972). Reflective, processedkaolin particle films (PF) are used to repel insects and reduce sunburn damage (Glenn and Puterka, 2005) but have had variable effects on other fruit quality attributes. Glenn et al. (2001) have shown that fruit color was enhanced in east coast trials by PF but fruit color was unaffected in studies in Washington. Andrew et al. (2004) improved apple grade with PF treatments. However, Schupp et al. (2002) found that a PF reduced fruit size, red color, and sunburn in 'Fuji' apple in Idaho; while in New York, early season applications of PF had no effect on fruit size or color in 'Honeycrisp' and late season applications reduced fruit size and red color. Characteristics of the particle film will influence plant response. Applications of Surround WP that leave discrete spots of heavy residue on the fruit will block light and reduce color development beneath the heavy deposition (unpublished data), so it is important that a thin, uniform particle film be deposited on the leaves and fruit with the appropriate sprayer technology (Glenn and Puterka, 2005; 
Glenn et al., 2002). Apple color can be improved with evaporative cooling (Unrath, 1972), which lowers fruit surface temperature. PF reduced fruit surface temperature (Glenn et al., 2002 ) and canopy temperature (Glenn et al., 2003) and these properties may be important in improving fruit color development. Summer pruning, dwarfing rootstocks, and training systems also improve color development by increasing light transmission to the fruit surface (Blizzard et al., 1988; Heinicke, 1966). The reflective nature of the particle film reduces light transmission into the leaf (Glenn et al., 1999), but the PAR was not absorbed by the particles; rather, it was reflected and can be intercepted by other leaves and fruit (Glenn et al., 2003). Reduced fruit temperature and increased light scattering within apple canopies associated with PF may improve apple color development. The purpose of these studies was to examine the effect of $\mathrm{PF}$ applications on fruit quality of key cultivars on the east and west coasts of the U.S.

\section{Methods and materials}

\section{Study 1. Application to 'Empire' in West Virginia}

Apple trees received applications of a highly reflective, white, hydrophilic particle-based kaolin mineral (Surround WP; Engelhard Corp., Iselin, N.J.) in addition to a conventional pesticide spray program. The kaolin mineral is processed to a bright white color of $>90 \%$ reflectance, with mean particle size $<2 \mu \mathrm{m}$ in diameter and is treated with a proprietary spreading and sticking agent. The PF treatments were applied using an orchard blast sprayer delivering $935.4 \mathrm{~L} \cdot \mathrm{ha}^{-1}$ (100 gal/acre). Surround WP concentration was $6 \%\left[56.0 \mathrm{~kg} \cdot \mathrm{ha}^{-1}(50 \mathrm{lb} / \mathrm{acre})\right]$ in 1999 and $2000 ; 3 \%$ [28.0 kg.ha- ${ }^{-1}(25$ $\mathrm{lb} / \mathrm{acre})]$ in 2001. Concurrent studies in 1999 and 2000 indicated that $3 \%$ concentration was sufficient for an effective PF (Glenn et al., 2002) and the concentration was reduced in 2001. PF treatments were applied weekly for 6 weeks following petal fall for the May through June treatment or every week for 6 weeks following petal fall and then every 2 weeks until harvest for the season-long treatment (12 applications). Control treatments were not sprayed.

The apple orchard was a moderate density planting [ 494.2 trees/ha (200 trees/acre)] of 'Empire'/'Malling 7A' ('M7A') planted in 1992 at the USDA/ARS Appalachian Fruit Research Station, Kearneysville, W.Va. The trees were not irrigated and were trained to a central leader. A separate group of trees were used in each year. In all years, the trees were hand-thinned post-bloom to adjust to a $100 \%$ crop load. All treatments were over-sprayed with conventional pesticides to insure no disease or insect damage. Conventional orchard practices were used in pruning and weed control. The experiment was a randomized block design with six single-tree plots in all years. A border tree separated each treatment tree. At fruit harvest, all fruit were weighed and counted in each plot. Twenty-five fruit were randomly collected from each tree for measurement of soluble solids concentration (SSC), starch index $(\mathrm{SI})$, and hue angle $\left(\mathrm{H}^{\circ}\right)$. Firmness was determined using a McCormick fruit firmness tester (model FT 327; EFFEGI Corp., Torino, Italy) equipped with a $11.1 \mathrm{~mm}(7 / 16$ inch $)$ probe. Skin color was determined with a Minolta Chroma meter (model CR221; Minolta Corp., Ramsey, N.J.) using the Hunter $\mathrm{L}^{*}, \mathrm{a}^{*}, \mathrm{~b}^{*}$ system and calculated $\mathrm{H}^{\circ}$ (Hunter and Harold, 1987) at four equally spaced locations around the equator of the fruit. SSC was determined from an aliquot of expressed juice of a longitudinal slice from each fruit. SSC was measured with an Abbe type refractometer (model 10450; American Optical Scientific Instruments Div., Buffalo, N.Y.) with a sucrose scale calibrated at $20^{\circ} \mathrm{C}(68.0$ $\left.{ }^{\circ} \mathrm{F}\right)$. Starch hydrolysis was determined using a rating scale of 1 to 9 after reaction with iodine, similar to others (Washington Apple Maturity Program, 1993). Trees were hand-thinned to approximately the same fruit load but the treatment response was refined with analysis of covariance to utilize the number of fruit per tree as an independent, quantitative factor in the analysis since average fruit size is inversely related to the number of fruit on the tree. Analysis of covariance estimates the mean response (fruit weight) for the mean number of fruit per tree averaged over all treatments. Fruit weight was analyzed using analysis of covariance in a randomized complete-block design using SAS. Adjusted treatment means were compared using least squares means from the analysis of covariance.
Treatment means were compared using Fisher's protected least significant difference (LSD).

Taste panel evaluation of 'EMPIRE'. 'Empire' fruit from the untreated control and season-long PF treatments were used in a taste panel evaluation following harvest. A random subsample of harvested fruit was placed in cold storage for 3 weeks. On each day of the taste panel evaluation, firmness measurements were made on five apples from each replicate of the two treatments with a McCormick fruit firmness tester fitted with an $11.1-\mathrm{mm}$ tip and mounted in a manual press. The expressed juice was collected and SSC was determined with an Atago digital refractometer. The same five apples were then washed with tap water and dried with cotton towels. The five apples from each treatment within a replication were cut into eighths, the two pieces containing the firmness test punctures were discarded, the core area was removed from each remaining slice, and the slices were combined in a plastic bowl. Two wedges from each of the six lots were placed in paper serving cups labeled with three-digit numbers.

Sensory evaluations were performed by 127 volunteer panelists from the staff of the Beltsville Agricultural Research Center, Beltsville, Md. who said that they liked and frequently consumed apples. Ten panelists attended each of 13 sessions. Each panelist evaluated six samples, representing two treatments $\times$ three replicates, so each panelist represented a complete block. Samples were presented one at a time. Serving order was uniform within a session and randomized between sessions. After consulting with a statistician, replicates were served in random order and treatment order within each replicate was alternated, so sample positions were balanced over the experiment. This arrangement permitted us to contrast the two treatments of a single field replicate while maintaining adequate randomization.

Evaluations were held in a sensory laboratory in booths under average office fluorescent lighting. Panelists were instructed to take a bite of lowsalt saltine cracker and a sip of water before tasting each sample. A sample consisted of two slices drawn from the combined slices of five apples and panelists were required to taste both slices before making a judgment. They scored intensity of 1 ) crispness, 2) apple 
flavor, 3) sweetness, 4) sourness, and 5 ) skin toughness; then they scored overall eating quality. All intensity parameters and eating quality were scored by marking unstructured line scales on a computer monitor using Compusense five (Compusense, Inc., Guelph, Ont., Canada). Intensity scales were labeled none to very much and eating quality was labeled bad to excellent, recorded as 0 to 100 points, respectively.

\section{Study 2. Season-long PF application to three apple cultivars}

Kearneysville, W.VA. Surround WP was applied, starting at petal fall, every week for 6 weeks and then every 2 weeks to 'Gala' and 'Fuji' apple trees on 'Malling 9' rootstock planted in 1995 and spaced $2 \times 4.3 \mathrm{~m}(6.6 \times 14 \mathrm{ft})$. The PF treatments were applied using an orchard blast sprayer delivering 935.4 $\mathrm{L} \cdot \mathrm{ha}^{-1}$. Surround WP concentration was $6 \%$ in $2000\left(56.0 \mathrm{~kg} \cdot \mathrm{ha}^{-1}\right) ; 3 \%$ in $2001\left(28.0 \mathrm{~kg} \cdot \mathrm{ha}^{-1}\right)$. Surround was applied to six trees each of 'Gala' and 'Fuji' and six trees of each were used as nontreated controls in a completely randomized design with six single-tree replicates. At harvest, 11 fruit were collected from each cultivar and replicate. All fruit were used for quality evaluation. Quality factors evaluated were SI, weight, firmness, $\mathrm{H}^{\circ}$, and SSC as described in the previous experiment. All fruit were weighed and counted in each plot to measure yield per tree. Fruit numbers per tree were reduced in 2000 by spring frosts.

Wenatchee, Wash. Surround WP (28.0 kg.ha-1) was applied, starting at petal fall, every 2 weeks to 'Cameo', 'Gala', and 'Fuji' apple trees in 2001. The PF treatments were applied using an orchard blast sprayer delivering 935.4 $\mathrm{L} \cdot \mathrm{ha}^{-1}$. All the trees used in this study were located at the USDA, ARS experimental plots in Wenatchee, Wash. 'Cameo' and 'Fuji' trees were on 'Malling 26' rootstock and 'Gala' was on 'M.7A'. Surround WP was applied to 15 trees of both 'Cameo' and 'Fuji' and 15 trees were used as controls in a completely randomized design with single-tree replications. Surround WP was applied to six trees of 'Gala' and six trees were used as nontreated controls in a completely randomized design. At harvest, 10 fruit were collected from each cultivar and replicate. Crop load was visually assessed as: low (less than a full crop load); moderate (a full crop load); or excessive (inadequate fruit thinning resulting in an excessive crop load). A full crop load was defined as approximately two boxes per tree of 100-count apples. Trees estimated to be carrying at least $25 \%$ less than this amount were judged as low, less than a full crop, while trees estimated to be carrying at least $25 \%$ more than this amount were judged as carrying an excessive crop. Quality factors evaluated were: SI, weight, firmness, $\mathrm{H}^{\circ}$, and SSC. SI was determined using a rating scale of 1 to 6 (Washington Apple Maturity Program, 1993). Firmness was determined at two locations per fruit with the TA-XT2 texture analyzer (Texture Technologies Corp. Scarsdale, N.Y.), equipped with a 11.1$\mathrm{mm}$ probe. $\mathrm{H}^{\circ}$ was determined with The Color Machine (Pacific Scientific, Silver Spring, Md.) using the Hunter $\mathrm{L}^{*}, \mathrm{a}^{*}, \mathrm{~b}^{*}$ system and calculated $\mathrm{H}^{\circ}$ (Hunter and Harold, 1987) at four equally spaced locations around the equator of the fruit. SSC were determined from an aliquot of expressed juice taken from a cross-sectional slice from each of the fruit. An Abbé type refractometer (model 10450; American Optical Scientific Instruments Div.) with a sucrose scale calibrated at $20^{\circ} \mathrm{C}$ was used to determine SSC.

\section{Results and discussion}

Fruit weight of PF season-long treatments was greater than the untreated control in 1999 and 2000 (Table 1). Fruit weight of the May to June PF treatment was greater than the control in 1999 only. In 2001, there was not a significant treatment difference. Trees were hand-thinned to approximately the same fruit load within each year and the treatment response can be isolated with analysis of covariance that utilizes the number of fruit per tree as an independent, quantitative factor in the analysis. Analysis of covariance estimates the mean response (fruit weight) for the mean number of fruit per tree averaged over all treatments within each year. The small divergences of the mean from the adjusted mean (Table 1 ) are an indication that the distribution of fruit number per tree was similar for the treatments within each year. Fruit firmness and SI were unaffected by the treatments in all years and only in 2001 was SSC influenced by PF treatment, where the PF May to June treatment had a small $(<1 \%)$ but significantly higher SSC that the control or season-long PF treatments. $\mathrm{H}^{\circ}$ was significantly and consistently reduced (more red color) by both of the PF treatments compared to the Control treatment in all years. In earlier studies (Glenn et al., 2001) 'Empire' red color was greatest when a PF treatment was initiated in May and continued throughout the season while initiating PF treatments later in the season had no effect on red color. The present study confirms these results and further supports the observation that particle film application early in the season (May to June) enhances 'Empire' red fruit color at harvest.

The $\mathrm{H}^{\circ}$ values measure red color and the lack of green color. If the green background were reduced for similar levels of red color, then the apparent $\mathrm{H}^{\circ}$ would decrease. The levels of green background color and skin chlorophyll were not measured in these studies. However, since SI and firmness were unaffected by the treatments, it is assumed that maturity and the fading of background color were equivalent in all treatments. Leaf chlorophyll has been unaffected by PF treatments in 'Empire' apple (Glenn et al., 2003).

Glenn et al. (2001) also demonstrated that fruit weight was greatest when PF treatments were initiated in May or June. The present study only indicated that PF treatments in May and June increased fruit weight in 1 of 3 years while season-long PF applications increased fruit weight in 2 of 3 years. These results, while confirming the beneficial effect of PF on yield, demonstrate that the environmental interactions results in inconsistent responses even at the same location.

Sensory panel scores demonstrated no differences in crispness, apple flavor, sweetness, sourness, skin toughness or in the overall eating quality of Surround WP treated apples compared to control. There were no differences in SSC or firmness of these fruit, only color (Table 1) and apparently no eating quality differences.

Cultivar response to season-long $\mathrm{PF}$ applications varied with years and locations (Table 2). 'Gala' and 'Fuji' in West Virginia were alternate bearing with 2000 as the low yielding year and 2001 as the high yielding year. PF application increased fruit weight and red color for 'Gala' in 2001 in West Virginia. 'Fuji' had an increase in fruit weight and soluble solids with PF application in 2001 at the Washington 
Table 1. Fruit quality response of 'Empire' apple at harvest to the timing of particle film (PF) applications in 3 years at Kearneysville, W.Va.

\begin{tabular}{|c|c|c|c|c|c|c|c|c|c|}
\hline Year & Treatment $^{z}$ & $\begin{array}{c}\text { Total } \\
\text { fruit } \\
\text { (no./tree) } \\
\end{array}$ & $\begin{array}{c}\text { Yield } \\
\left(\mathrm{kg} / \text { tree }^{\mathrm{y}}\right. \\
\end{array}$ & $\begin{array}{c}\text { Fruit } \\
\text { wt } \\
(\mathrm{g})^{\mathrm{x}} \\
\end{array}$ & $\begin{array}{c}\text { Adjusted } \\
\text { fruit } \\
\text { wt (g) } \\
\end{array}$ & $\begin{array}{c}\text { Hue } \\
\text { angle }\end{array}$ & $\begin{array}{l}\text { Firmness } \\
(\mathrm{N})^{\mathrm{w}}\end{array}$ & $\begin{array}{c}\text { Soluble } \\
\text { solids } \\
\text { concn }(\%)\end{array}$ & $\begin{array}{r}\text { Starch } \\
\text { index }\end{array}$ \\
\hline \multirow[t]{3}{*}{1999} & Control & 428 & 47 & $108.9 \mathrm{~b}^{\mathrm{v}}$ & $106.7 \mathrm{~b}^{\mathrm{u}}$ & $39.0 \mathrm{a}$ & 73.8 & 12 & 6 \\
\hline & Surround WP (season-long) & 392 & 52 & $131.4 \mathrm{a}$ & $131.0 \mathrm{a}$ & $32.7 \mathrm{~b}$ & 75.2 & 12.4 & 6 \\
\hline & Surround WP (May-June) & 372 & 49 & $130.9 \mathrm{a}$ & $131.8 \mathrm{a}$ & $32.3 \mathrm{~b}$ & 73.8 & 12.1 & 6 \\
\hline \multirow[t]{3}{*}{2000} & Control & 1821 & 224 & $123.0 \mathrm{~b}$ & $123.2 \mathrm{~b}$ & $69.0 \mathrm{a}$ & 68.9 & 11.4 & 7 \\
\hline & Surround WP (season-long) & 1909 & 256 & $134.2 \mathrm{a}$ & $134.6 \mathrm{a}$ & $54.0 \mathrm{~b}$ & 68.9 & 11.3 & 7 \\
\hline & Surround WP (May-June) & 1513 & 187 & $123.5 \mathrm{~b}$ & $124.2 \mathrm{~b}$ & $56.6 \mathrm{~b}$ & 70.3 & 11.5 & 7 \\
\hline \multirow[t]{3}{*}{2001} & Control & 1078 & 165 & 152.8 & 153.5 & $40.5 \mathrm{a}$ & 66.3 & $12.3 \mathrm{~b}$ & 8 \\
\hline & Surround WP (season-long) & 969 & 152 & 157 & 155.5 & $32.8 \mathrm{~b}$ & 68.1 & $12.5 \mathrm{~b}$ & 8 \\
\hline & Surround WP (May-June) & 1017 & 157 & 154.5 & 154.8 & $30.0 \mathrm{~b}$ & 68.1 & $13.1 \mathrm{a}$ & 8 \\
\hline
\end{tabular}

${ }^{2}$ The PF treatments were applied using an orchard blast sprayer delivering $935.4 \mathrm{~L} \cdot \mathrm{ha}^{-1}(100 \mathrm{gal} / \mathrm{acre})$. Surround WP concentration was $6 \%\left[56.0 \mathrm{~kg} \cdot \mathrm{ha} \mathrm{a}^{-1}(50 \mathrm{lb} / \mathrm{acre})\right]$ in 1999 and $2000 ; 3 \%\left[28.0 \mathrm{~kg} \cdot \mathrm{ha}^{-1}(25 \mathrm{lb} / \mathrm{acre})\right]$ in 2001 . The control was untreated.

${ }^{\mathrm{y}} 1.0 \mathrm{~kg}=2.205 \mathrm{lb}$.

$\mathrm{x} 1.0 \mathrm{~g}=0.035 \mathrm{oz}$.

w $1.0 \mathrm{~N}=0.225 \mathrm{lbf}$

'Mean separation within year using Fisher's protected least significant difference $(P=0.05)$.

"Indicates a significant difference $(P=0.05)$ based on analysis of covariance using the number of fruit per tree as the covariate. Values are adjusted means based on the mean number of fruit per tree.

Table 2. Fruit quality response at harvest of three cultivars in two locations to season-long particle film (PF) treatment in 2000 and 2001.

\begin{tabular}{|c|c|c|c|c|c|c|c|c|}
\hline Treatment $^{\mathrm{z}}$ & Location & Year & $\begin{array}{l}\text { Firmness } \\
(\mathrm{N})^{\mathrm{y}}\end{array}$ & $\begin{array}{c}\text { Soluble solids } \\
(\%)\end{array}$ & $\begin{array}{c}\text { Hue } \\
\text { angle }\end{array}$ & $\begin{array}{c}\text { Fruit } \\
w_{t}(g)^{x}\end{array}$ & $\begin{array}{l}\text { Starch } \\
\text { index }\end{array}$ & $\begin{array}{c}\text { Yield } \\
(\mathrm{kg} / \text { tree })^{w}\end{array}$ \\
\hline \multicolumn{9}{|c|}{ Gala } \\
\hline Control & WV & 2000 & 83.2 & 15.2 & 28.9 & 156.7 & 7 & 15 \\
\hline Surround WP & WV & 2000 & 80.1 & 15.1 & 31.9 & 157.4 & 7 & 21 \\
\hline Control & WV & 2001 & 72.5 & 12.4 & 37.4 & 125.5 & 6 & 43 \\
\hline Surround WP & WV & 2001 & 77.0 & 13.0 & $32.3^{* * \mathrm{v}}$ & $137.4^{*}$ & 6 & 58 \\
\hline Control & WA & 2001 & 66.0 & 15.5 & 33.3 & 247.7 & 5 & Moderate $^{\mathrm{u}}$ \\
\hline Surround WP & WA & 2001 & 62.9 & 14.8 & 35.1 & 218.1 & 5 & Moderate \\
\hline \multicolumn{9}{|c|}{ Fuji } \\
\hline Control & WV & 2000 & 78.7 & 15.3 & 74.9 & 205.3 & 8 & 14 \\
\hline Surround WP & WV & 2000 & 78.7 & 15.3 & 72.6 & 198.1 & 7 & 14 \\
\hline Control & WV & 2001 & 71.6 & 12.9 & 66.1 & 163.6 & 8 & 53 \\
\hline Surround WP & WV & 2001 & 70.3 & 13.1 & 62.2 & 167.4 & 7 & $80^{*}$ \\
\hline Surround WP & WA & 2001 & 69.0 & $14.6^{* *}$ & 57.3 & $254.8^{* *}$ & 3 & Excessive \\
\hline \multicolumn{9}{|c|}{ Cameo } \\
\hline Control & WA & 2001 & 69.9 & 13.8 & 53.4 & 260.0 & 3 & Moderate \\
\hline Surround WP & WA & 2001 & 70.9 & $15.2^{* *}$ & $49.4^{* *}$ & 256.0 & $4^{* *}$ & Moderate \\
\hline $\begin{array}{l}{ }^{2} \text { The PF treatment } \\
\mathrm{lb} / \text { acre })] ; 3 \% \text { in } 20 \\
\text { y } 1.0 \mathrm{~N}=0.225 \mathrm{lbf} \text {. } \\
{ }^{\mathrm{x}} 1.0 \mathrm{~g}=0.035 \mathrm{oz} . \\
{ }^{\mathrm{w}} 1.0 \mathrm{~kg}=2.205 \mathrm{lb} \text {. } \\
{ }^{\mathrm{v}} \mathrm{Mean} \text { separation } \mathrm{w} \\
{ }^{\mathrm{u} Y i e l d} \text { was visually } \\
{ }^{*}{ }^{* *} \text { Significant at } P\end{array}$ & $\begin{array}{l}\text { ere applied us } \\
{\left[28.0 \mathrm{~kg} \cdot \mathrm{ha}^{-1}\right.} \\
\text { n year, cultiva } \\
\text { sed as: low (l }\end{array}$ & $\begin{array}{l}\text { orchard } \\
\text { acre)]. } \\
\text { ocation }\end{array}$ & est. & $.4 \mathrm{~L}^{2} \mathrm{ha}^{-1}(100 \mathrm{gal}$ & ). Surroun & concentrati & $56 \%$ in 2 & $56.0 \mathrm{~kg} \cdot \mathrm{ha}^{-1}(50$ \\
\hline
\end{tabular}

site when the crop load was excessive. 'Cameo' had an increase in soluble solids, starch index, and red color in Washington with the PF application under moderate crop loads. It appears that under heavy crop loads, PF treatments may improve color and/or fruit size. PF treatments can increase carbon assimilation with partitioning of the assimilate to the fruit by reduc- ing canopy temperature and increasing stomatal conductance (Glenn et al., 2001, 2003, 2005).

'Empire' consistently had improved red color with season-long PF applications, while other cultivars had inconsistent responses in the present studies and earlier work. It is important to note that PF application to apples did not reduce color in these stud- ies. 'Empire' is considered a difficult fruit in which to increase size and color (Blizzard et al., 1988; Goffinet et al., 1995; Schupp et al., 2002) and maybe more responsive to a $\mathrm{PF}$ treatment that reduces stress (Glenn et al., 2001, 2002, 2003). 'Gala' and 'Fuji' are grown worldwide and are likely more tolerant of a wide range of environmental stresses. Therefore, the 
cultivar response to $\mathrm{PF}$ applications is generally variable due to the interaction with seasonal environmental characteristics and crop load. While particle film technology has value for insect control and reducing sunburn, it has limited value for enhancing fruit color, due to the inconsistent response.

\section{Literature cited}

Abeles, F.B., P.W. Morgan, and M.E. Saltveit Jr. 1992. Ethylene in plant biology, 2nd ed. Academic Press, New York.

Andrews, T.L., M.E. Muller, B.R. Dodson, M.R. Ellersieck, and M. Kaps. 2004. A kaolin-based particle film suppresses certain insect and fungal pests while reducing heat stress in apples. J Amer. Pomol. Soc. $58: 42-51$.

Boynton, D. and A.B. Burrell. 1944. Effects of nitrogen fertilization on leaf nitrogen, fruit color and yield in two New York 'McIntosh' apple orchards, 1942 and 1943. Proc. Amer. Soc. Hort. Sci. 44:25-30.

Blizzard, S.H., S. Singha, T.A. Baugher, and B.D. Cayton. 1988. Yield and fruit quality of apple trees under three high density management systems. Fruit Var. J. 42:67-72.

Glenn, D.M. and G.J. Puterka. 2005. Particle film technology: A new tool for agriculture. Hort. Rev. 31:1-45.

Glenn, D.M., A. Erez, G.J. Puterka, and P. Gundrum. 2003. Particle films affect carbon assimilation and yield in 'Empire' apple. J. Amer. Soc. Hort. Sci. 128:356-362.

Glenn, D.M., E. Prado, A. Erez, J. McFerson, and G.J. Puterka. 2002. Effect of a reflective, processed-kaolin particle film on fruit temperature, radiation reflection and solar injury in apple. J. Amer. Soc. Hort. Sci. 127:1-6.

Glenn, D.M., G.J. Puterka, S. Drake, T.R. Unruh, A.L. Knight, P. Baherle, E. Prado, and T. Baugher. 2001. Particle film application influences apple leaf physiology, fruit yield and fruit quality. J. Amer. Soc. Hort. Sci. 126:175-181.
Glenn, D.M., F.J. Puterka, T. van der Zwet, R.E. Byers, and C. Feldhake. 1999. Hydrophobic particle films: A new paradigm for suppression of arthropod pests and plant diseases. J. Econ. Entomol. 92:759-771.

Goffinet, M.C., T.L. Robinson, and A.N Lakso. 1995. A comparison of 'Empire' apple fruit size and anatomy in unthinned and hand-thinned trees. J. Hort. Sci. 70:375-387.

Heinicke, D.R. 1966. Characteristics of McIntosh and Red Delicious apples as influenced by exposure to sunlight during the growing season. Proc. Amer. Soc. Hort. Sci. 89:10-13.

Hunter, R.S. and R.W. Harold. 1987. The measurement of appearance, 2 nd ed. Wiley, New York.

Schupp, J.R., E. Fallahi, and I. Chun. 2002. Effect of particle film on fruit sunburn, maturity and quality of 'Fuji' and 'Honeycrisp' apples. HortTechnology 12:87-90.

Robinson, T.L., A.N. Lakso, and S.G. Carpenter. 1991. Canopy development, yield, and fruit quality of 'Empire' and 'Delicious' apple trees grown in four orchard production systems for ten years. J. Amer. Soc. Hort. Sci. 116:179-187.

Unrath, C.R. 1972. The quality of 'Red Delicious' apples as affected by overtree sprinkler irrigation. J. Amer. Soc. Hort. Sci. 97:58-61.

Walter, T.E. 1967. Factors affecting fruit color in apples: A review of world literature. Rpt. East Malling Sta. 1966:70-82.

Washington Apple Maturity Program. 1993. Washington apple maturity handbook. Washington Apple Maturity Program, Wenatchee. 